\title{
Monitoring inner London mental illness services
}

\author{
MILMIS Project Group
}

\begin{abstract}
Our objective was to establish a mechanism for monitoring indicators of the state of hecith of inner London's mental illnoss services. Data were collected for a census week around 15 June 1994. Local dato collection was coordinated by consultiant pyschiatrists working in inner London services. Twelve services participated with a combined catchment population of $2.6 \mathrm{~m}$. They included ten London services which were among the 17 most socially depitved areas of Engtand. Main indicators were admisston bed occupancy levels (including an estimate of the fotal requirement), proportion of patients detained under the Mental Health Act, number of asscults commilted by inpationts, number of emergency assessments and CPN caseloads. The mean true bed occupancy (which reflects the number of patients who were recelving, or required, in-patient care on census dory was 130\%. To meet all need for acute poychiatric care, including for patients who should have been admilted and those discharged prematurely because beds were full, a further 426 beds would hove been required. Filly per cent of patients were legally detained. Physical assoults were virtually a dally occurrence on the admission units. Average community pyschiatric nurse caseloads were 37. suggesting that the majortly were not working intensively with limited caseloads of pattients with severe mental Illiness. These indicators, although imperfect, will allow for some measurement of the impact of local and central initiatives on the poor state of London's mental lilness services.
\end{abstract}

The state of London's mental illness services is under close scrutiny. Recent reports have commented on the high occupancy levels of admission beds (Royal College of Psychiatrists, 1992; Hollander \& Tobiansky, 1990); the concentrating effect of bed closures resulting in wards containing a high proportion of disturbed young patients detained under the Mental Health Act (Patrick et al, 1989); the high number of violent incidents on psychiatric wards (Walker \& Seifert, 1994); the unavailability of low and medium secure provision (Coid, personal communication) and poor implementation of the Care Programme Approach (Association of Metropolition Authorities, 1993; North et al, 1993).

The attention of the media has been focused on mental health services, and those of London in particular, by the cases of Benjamin Silcock and Christopher Clunis which have highlighted difficulties and deficiencies in community care arrangements.

The government has responded to these issues in a number of ways. In response to the Clunis inquiry, the Health Secretary announced an additional $\$ 10 \mathrm{~m}$ for community-based mental health services in London and a further $\$ 20 \mathrm{~m}$ for the development of services for mentally ill people in London who are homeless. The London Implementation Group has established a Mental Health Reference Group and the Mental Health Task Force has reviewed the state of London services and will be reporting shortly. Also, the requirement that supervision registers be introduced by 1 October 1994 (NHSME, 1994) will be of particular relevance, and pose a particular challenge, to inner city services.

At present no mechanism exists for monitoring the state of London's mental illness services or for gauging the effect that the various initiatives have upon it. The health service data collected at present are inadequate for this purpose (House of Commons Health Committee, 1994; DOH 1993). They are crude, for example they cannot allow calculation of true bed occupancy or caseloads of community workers; they are published several years after collection and they are almost certainly incomplete and inaccurate.

In response to this absence of quantifiable and reliable information, a group of London psychiatrists met and established a mechanism for monitoring a few key indicators that would provide timely and repeated information about the health of their services. 


\section{The project}

\section{The services}

Psychiatrists from 13 NHS trusts were invited to participate in the project, only one declined. The project targeted inner London services and as a result the participants included ten of the 17 most socially deprived districts in the country, as gauged by the Jarman Underprivileged Area Score (UPA8).

\section{The monitoring procedure}

A draft monitoring schedule was discussed and revised at a meeting of the participants. 15 June 1994 was identified as the first census day on which the psychiatrists collected data about their services for mentally ill people aged 18-64. They also gathered further data on service activity over a week, either during the week before or the week after the census day.

\section{The schedule}

The monitoring schedule is available from the corresponding author. It was kept as brief as possible to facilitate rapid completion and focused on data about service use and activity that could be collected quite easily.

Information was collected on the census day about the normal complement of admission beds and the number of additional beds that had been set up because these were full. The number of patients in the admission unit on that day, and how many were detained under the Mental Health Act, was recorded together with the number of patients who should have been in the admission unit that day but were at home, in prison or occupying beds elsewhere, because local admission beds were full. To supplement this information, participants were also asked to count the number of patients seen during the census week who either should have been admitted but were not, because no bed was avallable, or who were discharged prematurely to make way for a more urgent admission.

Participants also provided information about the composition of crisis services, and the number of assessments made during census week and the caseloads of, and waiting times for, their community psychiatric nurses. Information was also gathered during census week on the number of incidents, involving patients on the admission wards, of assault, sexual harassment and self-harm.

The following indicators were dertved from the data.

\section{Bed occupancy (expressed as percentages)}

(a) Admission unit bed occupancy

Numerator $=$ number of patients on the admission unit list on census day.

Denominator $=$ normal complement of admission beds.

\section{(b) True bed occupancy}

Numerator $=$ number of patients on the admission unit list on census day+ patients who should have been in a bed on census day but were at home or in prison or in another hospital because admission beds were full.

Denominator $=$ normal complement of admission beds.

(c) Total requirement bed occupancy

Numerator $=$ number of patients on the admission unit list on census day+ patients who should have been in a bed on census day but were at home or in prison or in another hospital because admission beds were full + patients whose clinical state warranted admission during census week but who could not be admitted because beds were full+patients discharged prematurely during census week to make way for a new admission-patients on leave from admission unit who did not need a bed kept available.

Denominator $=$ normal complement of admission beds.

Proportion of patients detained under the Mental Health Act (expressed as a percentage)

Numerator $=$ number of patients on the admission unit list who were detained 
Table 1. MILMIS indicators for 12 Inner London mental Illness services

\begin{tabular}{|c|c|c|c|c|c|c|c|c|c|}
\hline \multirow[b]{2}{*}{ "Service No. } & \multicolumn{3}{|c|}{ Bed occupancy } & \multirow[b]{2}{*}{ Detained } & \multicolumn{2}{|c|}{ Violent incidents } & \multirow[b]{2}{*}{ Crisis assessments } & \multicolumn{2}{|c|}{ CPNs } \\
\hline & (a) & (b) & (c) & & (a) & (b) & & (a) & (b) \\
\hline $\begin{array}{c}1 \\
2 \\
3 \\
4 \\
5 \\
6 \\
7 \\
8 \\
9 \\
10 \\
11 \\
12\end{array}$ & $\begin{array}{l}126 \% \\
119 \% \\
106 \% \\
100 \% \\
100 \% \\
100 \% \\
130 \% \\
137 \% \\
122 \% \\
103 \% \\
114 \% \\
106 \%\end{array}$ & $\begin{array}{l}142 \% \\
131 \% \\
127 \% \\
102 \% \\
106 \% \\
136 \% \\
157 \% \\
156 \% \\
140 \% \\
127 \% \\
160 \% \\
109 \%\end{array}$ & $\begin{array}{l}153 \% \\
132 \% \\
130 \% \\
102 \% \\
106 \% \\
143 \% \\
177 \% \\
171 \% \\
154 \% \\
139 \% \\
207 \% \\
-\end{array}$ & $\begin{array}{l}34 \% \\
53 \% \\
68 \% \\
43 \% \\
31 \% \\
41 \% \\
56 \% \\
48 \% \\
41 \% \\
64 \% \\
53 \% \\
40 \%\end{array}$ & $\begin{array}{l}0.52(2.5) \\
0.65(2.6) \\
0.37(2.6) \\
0.76(2.7) \\
0.28(2.4) \\
0.53(1.9) \\
0.54(2.2) \\
0.14(3.1) \\
0.80(1.9) \\
1.93(9.9) \\
0.81(3.5) \\
-\end{array}$ & $\begin{array}{l}0 \\
0.16(0.6) \\
0.31(2.2) \\
0.61(2.2) \\
0 \\
0.13(0.5) \\
0.41(1.6) \\
0.41(0.9) \\
0 \\
1.01(5.2) \\
0.47(2.0) \\
0\end{array}$ & $\begin{array}{r}1 \\
28 \\
54 \\
17 \\
4 \\
24 \\
50 \\
12 \\
22 \\
8 \\
3 \\
43\end{array}$ & $\begin{array}{l}42 \\
22 \\
32 \\
37 \\
30 \\
62 \\
50 \\
40 \\
40 \\
22 \\
44 \\
17\end{array}$ & $\begin{array}{r}6 \\
10 \\
2 \\
7 \\
7 \\
14 \\
14 \\
8 \\
8 \\
5 \\
13 \\
16 \\
7\end{array}$ \\
\hline "Means & $111 \%$ & $130 \%$ & $140 \%$ & $50 \%$ & $0.60(2.5)$ & $0.33(1.4)$ & 23 & 37 & 9 \\
\hline
\end{tabular}

- See text for explanation of categorles.

"Means. These refer to the whole sample, l.e. refer to the combined catchment populations and bed complements.

under the Mental Health Act on census day.

Denominator $=$ total number of patients on the admission unit list on census day.

Assaults involving in-patients: expressed as number of incidents per 10 beds (and number per 100,000 catchment population)

(a) First-degree assault - assault resulting in no detectable injury.

(b) Second-degree-assault resulting in minor physical injurles such as bruising. abrasions or small lacerations.

(c) Third-degree assault - assault resulting in major physical injuries including large lacerations, fracture, loss of consciousness, or any assault requiring subsequent medical investigation or treatment.

\section{Crisis/emergency assessments} (expressed as number of assessments per 100,000 catchment population)

These were defined as assessments carried out by the Individual or team available to assess patients with severe mental illness who require urgent assessment (within two hours) for relapse/problems sufficiently severe for admission to be considered.

\section{Community psychiatric nurses (CPNs)}

(a) Average caseload of CPNs.

(b) Waiting time for first appointment with CPN (in days).

\section{Findinge}

The mean UPA8 score of the catchment areas of participating services was 138 (range 118-163) and their combined catchment population was $2.6 \mathrm{~m}$. The services had a combined normal complement of 1109 admission beds, a mean of 42 beds per 100,000 population (range 24-77). Of the 1236 patients recorded as being in-patients in admission units on census day, 621 (50\%) were detained under the Mental Health Act: $339(27 \%)$ had been in hospital for 3-6 months, $101(8 \%)$ for 6-12 months and 43 (4\%) for more than 12 months.

Table 1 shows the participating services' scores on the indicators. Since only one incident of third degree violence was reported, this indicator is omitted. 


\section{Bed occupancy}

The mean true bed occupancy was $130 \%$ (range 102\%-160\%) and the mean total requirement bed occupancy was $140 \%$ (range 102\%-207\%). The latter represented a requirement for an additional 426 admission beds (16 per 100,000 population) to meet demand during census week. Because admission beds were full, 204 patients were lodged elsewhere; 53 in non-admission psychiatric beds within the same trust, five in medical wards, 42 in other NHS hospitals, 60 in private psychiatric hospitals, 30 at home or in community settings and 14 in prisons or police cells. For the same reason, nine services reported that a total of 84 patients, whom clinicians thought required admitting, could not be admitted during census week and a further 24 patients were discharged prematurely.

\section{Violent incidents}

A total of 105 assaults were reported over the week of the census; 67 were first-degree, 37 second-degree and one third-degree. There were also 53 incidents of sexual harassment, eight of sexual assault (six of which were in one district) and 34 incidents of self-harm recorded during the same period. In addition there were 281 reported incidents of verbal assault or damage to property. Data on sexual assault and harassment and verbal assault/ damage to property were considered too unreliable to be used as indicators.

\section{Crisis/emergency assessments}

During census week 619 such assessments were made, a mean of 23 per 100,000 population. Services reported a wide range on this indicator (1-54 per 100,000 population) suggesting that further definition might be required.

\section{Community psychiatric nurses}

The average reported caseload of CPNs in participating services was 37 (range 17-62). This indicator was considered unreliable as each service had its own configuration of CPN services and some individual services had groups of CPNs who performed different roles (e.g. crisis intervention $v$. routine support). Despite high caseloads, services did not report excessive waiting times for patients to see CPNs - the mean wait was nine days (range
2-16 days) (this figure does not take into account the waiting times for emergency responses which for the majority of services was within a couple of hours).

\section{Comment}

Some of the MILMIS indicators are more robust than others. Those relating to bed occupancy are likely to be accurate, the data collection having been supervised by clinical workers in those services. Those relating to activity and events over census week are likely to be less reliable, based as they are on the subjective report of a number of clinical workers in each service. The indicators cannot be validated against any other data source: as mentioned in the introduction, nationally collected data do not allow for estimation of bed occupancies and physical assaults tend to be under-reported by procedures for routine monitoring of incidents (Walker \& Seifert, 1994).

The high level of disturbance in admission units is compounded by the unavailability of medium secure beds, making the transfer of patients, for whom this is a desirable option. very difficult. A separate survey, conducted by Coid on 21 June 1994 (personal communication), measured occupancy levels of the four Thames regions' NHS medium secure beds during the census week. Forty-eight people were awaiting transfer to these beds; eight from other NHS beds, 19 from special hospitals and 21 from prison. This gave a true medium secure bed occupancy of $121 \%$. A further 90 patients from the Thames regions were in private medium secure facilities giving a total requirement medium secure bed occupancy of $162 \%$.

The definition of an indicator for the MILMIS project is dertved from that adopted by the Joint Commission on Accreditation of Healthcare Organizations (1989) - “A measurement tool used to monitor and evaluate important aspects of health care. It is not a direct measure of quality, but a flag directing attention to specific performance issues within an organisation, and which should be subject to more intense review".

The MILMIS indicators highlight the extent of the problems facing London's mental illness services, they do not identify their causes. For example:

High bed occupancy may be due to inappropriate admissions, inefficient 
clinical assessment and treatment leading to prolonged lengths of stay, inadequate community services causing bed blocking. too few beds or a combination of any or all of these.

High rates of violence and sexual harassment may be due to one or a combination of: over-crowding, inappropriate ward design, the absence of a range of facilities (such as intensive care areas and single-sex wards), difficulties in accessing secure provision or the need for better training or more nursing staff.

High CPN caseloads may be due to there being too few CPNs or to CPNs working with large numbers of the less severely mentally ill rather than targeting those with severe mental illness for intensive care.

None of these findings will be news to those who work in inner London services but, for the first time, some of the problems can be quantified, and therefore monitored, as central and local initiatives are instigated.

The identification of causes for these disturbing findings, and for provision of the remedies, is the responsibility of local clinicians through clinical audit, service managers through service activity monitoring, commissioning agencies through needs assessment and the government through resource allocation. The MILMIS Project Group intend to repeat the monitoring exercise at six monthly intervals to assess the effectiveness of such interventions.

\section{Conclusion}

These findings reflect the poor state of health of inner London's mental illness services. They tell us that during census week, the admission wards of these services were full and that many patients were in both NHS and private beds outside the local service. As a result of the pressure on beds, it was routine for patients, whom clinicians thought required in-patient care, not to be admitted and for a number of patients to be discharged prematurely. Admission wards are not places of haven but disturbed and dangerous environments, for both patients and staff, in which half the patients are legally detained and assault and sexual harassment are daily occurrences.

\section{Acknowledgement}

This project was supported by funding from the Royal College of Psychiatrists.

\section{References}

Association of METROPOLTAN Authormies (1993) Mental Health Services: issues for local government.

Department of HealTh (1993) Public Health Information Strategy: improving information on mental health. Department of Health.

HOLLANDER, D. \& TOBIANSKY, R. (1990) Crisis in admission beds. British Medical Journal, $\mathbf{3 0 1}, 664$

House of COMmons HeALTH COMmTTEe (1994) Better Off in the Community? The care of people who are seriously mentally ill. Volume 1. London: HMSO.

JOINT COMMISSION ON ACCREDTTATION OF HEALTHCARE ORGANIZATIONS (1989) Characteristics of clinical indicators. Quarterly Review Bulletin, 18, 330-339.

NHSME (1994) Introduction of Supervision Registers for Mentally II People from 1 April 1994. HSG(94)5.

NORTH. C., RITCHE, J. \& WARD. K. (1993) Factors Influencing the Implementation of the Care Programme Approach. HMSO.

PATRICK, M., HiggrtT, A. \& Holloway, F. (1989) Changes in an inner city psychiatric in-patient service following bed losses: A follow-up of the East Lambeth 1986 survey. Health Trends, 21, 121-123.

Royal COLLGE OF PSYCHIATRIST (1992) Facilities and Services for Patients who have Chronic Persisting Severe Disabilities Resulting from Mental Illness. Councll Report CR19. 17 Belgrave Square, London SW1 8PG.

WALKER, Z. \& SEIFERT, R. (1994) Violent incidents in a psychiatric care unit. British Journal of Psychiatry, 164. 826-828.

MILMIS Project Group

Mr Bernard Audini, Dr Michael Crowe, Dr Joan Feldman, Dr Anna Higgitt, Dr Andrew Kent, Dr Paul Lelliott, Dr Heather McKee, Dr Stirling Moorey, Dr Eleni Palazidou, Dr Steven Pilling, Dr David Roy, Dr Robert Schapira, Dr Ram Seth and Dr Malcolm Weller

Correspondence to Dr Paul Lelliott, Research Unit, Royal College of Psychiatrists, 11 Grosvenor Crescent, London SWIX 7EE 